\title{
SOME RR LYRAE VARIABLES WITH BLAŽKO EFFECT
}

\author{
G. H. CHIS and V. URECHE \\ University of Cluj, Roumania
}

\begin{abstract}
Observations of some RR Lyrae stars with varying periods and shapes of the light curves were discussed. These are:

TU Com (Ureche, V., 1965)

WY Dra (Chis, D., Chis, G. H., and Mihoc, I. (1974))

SW Psc (Ureche, V. (1971a, b))
\end{abstract}

\section{References}

Chis, D., Chis, G. H., and Mihoc, I.: 1975, Inf. Bull. Var. Stars, No. 960.

Ureche, V.: 1965, Studia Univ. Babes-Bolyai, sr mat.-phys. fasc. 1, 73.

Ureche, V.: 1971a, Inf. Bull. Comm. 27 No. 532.

Ureche, V.: 1972b, Studii Cerc. Astr. 16, 141. 